\title{
Tailored reduced kinetic mechanisms for atmospheric chemistry modeling
}

\author{
L. M. T. Joelsson*, C. Pichler, E. J. K. Nilsson \\ Department of Physics, Combustion Physics, Lund University, Box 118, SE-221 00 Lund, \\ Sweden
}

\begin{abstract}
Reduced chemical kinetic mechanisms are essential for atmospheric chemistry modeling where use of explicit kinetic schemes are too computationally demanding. By tailoring of mechanisms to specific cases, mechanism size can be kept small, without significant loss of accuracy in predictions of selected species' concentrations. In the present work we present small kinetic mechanisms tailored using a novel method.

The reduced mechanisms are generated by applying the method to several cases previously described in the literature and their performance in box model simulations are evaluated. The characteristics of the reduced mechanisms are examined. In addition, the method's sensitivity towards time scales, choice of trace gas species of interest; and $\mathrm{NO}_{x}$ regime are investigated.

The reduced mechanisms include $10 \%-30 \%$ of all the reactions in the relevant subset of the detailed chemical mechanism. Simulations with the reduced mechanisms typically yield no loss in accuracy of ozone concentration predictions and less than a $10 \%$ accuracy loss for the concentration predictions of nitrogen oxides for the cases over as long as five simulated days.

Mechanisms generated to predict the concentrations of few species, over short time scales, high $\mathrm{NO}_{x}$ conditions with no isoprene generally include fewer reactions than mechanisms generated to predict the concentrations of several

\footnotetext{
* Corresponding author

Email address: magnus.joelsson@forbrf.lth.se (E. J. K. Nilsson)
} 
species, over long time scales, in isoprene rich, low $\mathrm{NO}_{x}$ conditions.

Keywords: Box modeling, air pollution, reduced chemical kinetic mechanism, ant colony optimization

\section{Introduction}

Growing concern for emissions of air pollutants deteriorating local and regional air quality as well as greenhouse gases altering the Earth's radiation budget, has spurred development of computational modeling of the atmosphere 5 (e.g. Ginnebaugh et al., 2010; Naik et al., 2013). Modeling is a tool to understand atmospheric processes and a means of predicting trends in climate and air quality by extrapolation into the future. Accurate predictions of concentrations of various trace gases are important in order to provide proper decisions basis for policy-makers, both on local and regional air quality and on global climate issues (IPCC, 2013).

Coupled atmospheric chemistry-transport modeling is conducted at a wide range of spatial scales, from global (e.g. Emmons et al., 2010) and regional scales (Monks et al. 2009) to the street scale (Zhong et al., 2016a). The scale of the model domain put requirements on the chemical kinetic mechanism, since the (advection) time scale and spatial scale of a chemistry-transport system are coupled. In the present study, time scales of up to five days are considered and extra attention is paid to the urban local scale (i.e. street canyon) application, since the coupled chemistry-transport modeling in this setting is a rather new research topic with high demands on the chemical mechanisms. Also, local systems under short periods of time will experience a narrower span of conditions than a global system under long periods of time. A local scale model will therefore be especially suitable for a tailored reduction of its chemical description.

Reduction of kinetic mechanisms is commonly achieved via structural lumping (Gery et al. 1989), intermediate species lumping (Jenkin et al., 2008), emission lumping (Stockwell et al., 1997; Watson et al. 2008, Bright et al., 2013) or sensitivity analysis (present study). Several reduced chemical mechanisms have 
been presented in the literature, some described in a review of coupled street canyon modeling (Zhong et al., 2016a), some described in a comparison study of chemical mechanisms used in global models (Emmerson and Evans, 2009). The level of detail on the mechanisms vary from simple $\mathrm{O}_{3}-\mathrm{NO}_{x}$ chemistry (nitrogen oxides: $\left.\left[\mathrm{NO}_{x}\right]=[\mathrm{NO}]+\left[\mathrm{NO}_{2}\right]\right)$ to inclusion of a range of hydrocarbons.

Some street canyon air quality studies develop or use reduced mechanisms based on the Master Chemical Mechanism (MCM) family of mechanisms (Bright et al. 2013: Zhong et al. 2016b). MCM is an attempt to describe tropospheric 35 chemistry explicitly (Saunders et al. 2003 , Jenkin et al., 2003, MCM, 2018). The latest MCM version 3.3.1 (Jenkin et al., 2015) follow the photooxidation path of methane and 142 additional VOCs adding up to 16701 reactions and 5832 species. Other extensive mechanisms are the National Center for Atmospheric Research Master Mechanism (NCAR-MM) (Madronich and Calvert 40 1989, NCAR, 2018) and the Statewide Air Pollution Research Center Atmospheric Chemical Mechanisms (SAPRC) Carter, 2010, Carter and Heo, 2013. SAPRC, 2013). These mechanisms and more are briefly reviewed in Zhong et al. (2016a) and compared in Chen et al. (2010). The results of Chen et al. (2010) as well as of other studies (e.g. Emmerson and Carslaw, 2009; Whalley

45 et al. 2011) indicate that no mechanism thus far is able to perfectly replicate field measurement data in any given settings nor is there necessarily always a negative correlation between deviation from measurement and mechanism size. For example, hydrogen radical concentrations in low $\mathrm{NO}_{x}$ environments have proved elusive. The limitation of the parent mechanism will presumably be inherited in any reduced mechanism. Most of the street-scale simulations use mechanisms either originally developed for regional or global applications, such as the GEOS-Chem mechanism (Kim et al., 2012), or derived from such mechanisms, e.g. Reduced Chemistry Scheme (RCS) (Bright et al., 2013; Zhong et al., 2016b) and Complex Chemical Mechanism (CCMCFD) (Sanchez et al.

55 2016) which are derived from the Common Representative Intermediate (CRI) (Jenkin et al., 2008) and Regional Atmospheric Chemistry Mechanism (RACM) (Stockwell et al., 1997), respectively. 
When reducing mechanisms, there will always be a trade-off between accuracy and computational speed (which depend on the number of reactions and species included). A way to solve the need for accuracy but still keep the number of reactions and species low is to tailor mechanisms for a limited set of conditions with respect to emissions, concentrations, etc. Other important aspects of the tailoring procedure are the time scales for which the reduced mechanism is to be used and the compounds for which the concentrations are considered important to predict (target compounds). To our knowledge, the first automatically tailored mechanism to be used in a street canyon simulation, was CCMCFD, developed in by Sanchez et al. (2016) with the software CHEMATA (CHEmical Mechanism Adaptation to Tropospheric Applications) (Kirchner, 2005, Junier et al. 2005). CHEMATA takes species, their source strength, and kinetic data 70 as input to generate an explicit or lumped reduced mechanism. CHEMATA does not, however, consider other conditions such as time frames, solar radiation, and temperature (solar radiation and temperature is implicitly included in the kinetic data input, but does not, to our understanding, influence the selection of reactions or species) nor does it consider the interest of the user in terms of predictions of certain compounds. These conditions constrain the degree to which a mechanism can be reduced with utility as will be shown below. Moreover, advances in kinetic research (e.g. Yarwood et al., 2010, Carter and Heo, 2013 Jenkin et al. 2015) calls for continuous updating of the detailed mechanisms, eventually making the older versions and thus their reduced offspring outdated. The tailored approach will enable the reduced mechanisms to be in pace with the most recent detailed version of its parent mechanism franchise.

The aim of the present work is to evaluate the performance and describe the characteristics of tailored kinetic mechanisms for modeling of atmospheric chemistry. Reduced mechanisms generated for cases with different compositions of trace gases, values of temperature, relative humidity, and solar radiation influx, along with various time scales and sets of target compounds are evaluated and characterized. Differences among the reduced mechanisms, which presumably reflect their cases' $\mathrm{NO}_{x}$ regime, are given special attention. From evaluation 
of the mechanisms performance and characteristics, conclusions can be made current study, chemical kinetics mechanisms are tailored for six cases originally presented by Emmerson and Evans (2009) plus one high $\mathrm{NO}_{x}$ case (see Section 2.2 along with a mechanism tailored for all six cases combined. Mechanisms are also tailored for three time scales (see Section 2.3) and two target compound get compound concentrations), sizes (number of reactions), and characteristics (composition of reactions) are discussed (see Section 3).

\section{Methodology}

\subsection{Mechanism reduction and box modeling}

The kinetic mechanisms employed in the current study, are generated by reducing a detailed mechanism (henceforth called base mechanism) while limiting the consequential loss of precision of relevant predictions. Here, the base mechanism is MCM v3.3.1. The reduction method, denoted Ant Colony Reduction (ACR), is a semi-stochastic, statistical method based on the heuristic Ant Colony Optimization (ACO) concept (Dorigo et al., 1996, Dorigo and Birattari, 2011) and was recently developed for combustion physics applications (Pichler and Nilsson, 2018). The main idea behind the ACO algorithms is to mimic biological ant colonies' ability to find optimal trails between their anthill and some food resource by communications via the distribution of pheromones. Similarly, within ACR, simulated ants are set out to find optimal oxidation paths in a kinetic mechanism from an emitted compound (e.g. VOC or $\mathrm{NO}_{x}$ ) to an oxidation end product (e.g. water vapor, carbon dioxide, or aqueous phase nitric acid). A large number of functional reduced mechanisms are generated for each application of the method which partly allows the users to select the most suitable mechanism for their demands, partly allows the method to be improved recursively. The reduced mechanisms are evaluated via box model simulations. 
The reduction process is designed as such: All reactions in the base mechanism with one particular species (initially, this can be an emitted hydrocarbon) as reactant are listed. The reactions are ascribed weights calculated from a combination of static rate of production values and non-static "pheromone"values. The pheromone-value mimic the ant's pheromone trails, which intensities are used to communicate the utility of a certain path from the anthill to a food resource between individual ants and the ant colony. Thus, the artificial pheromone-value in the method is continuously re-calculated based on feedback data from the method itself (e.g. reduced mechanism performance and size).

Reactions important for an accurate description on the chemical system will hence gain more weight through the reduction process compared to less important reactions. A reaction is semi-stochastically selected according to their weight; this way an entire oxidation path is built up. The set of reactions collected through the process makes up the reduced mechanism. The reduced mechanism is evaluated by a box model simulation and is given an (average) root-mean-square score, see Eq. (1).

The accuracy (or score) of the mechanisms is defined as:

$$
\text { score } \equiv \frac{1}{n} \sum_{\mathrm{A}=\mathrm{X}_{1}, \mathrm{X}_{2}, \ldots, \mathrm{X}_{n}} 1-\sqrt{\frac{\left[\mathrm{[ \textrm {A } ] _ { \text { reduced } }}-1\right)^{2}}{[\mathrm{~A}]_{\text {base }}}}
$$

where $[\mathrm{A}]$ is the concentration of target compound A. The subscript reduced refers to predictions obtained with a simulation using the reduced mechanism, 135 in this case the subscript base refers to predictions (base predictions) obtained with a simulation using the base mechanism, but can also be concentrations obtained with measurements.

The box model used in the current study is a version of the chemical module of the Aerosol Dynamics, gas- and particle-phase chemistry model for laboratory ${ }_{140}$ CHAMber studies (ADCHAM) model (Roldin et al., 2014), where the aerosol sub-module is omitted. The model uses the Kinetic Pre-Processor (KPP) software (Damian et al., 2002). The photolysis constants are calculated with the Tropospheric Ultraviolet and Visible (TUV) Radiation Model (NCAR, 2018). 
In the process, a large number of reduced mechanisms (here, 6 000) are con-

that all the constructed reduced mechanisms are functional kinetic mechanisms even though the primary role of this abundancy in mechanism generation and scoring is to refine the overall reduction process. The reduced mechanisms span a range of sizes and corresponding accuracy, such that either a sufficiently small cation in question can be chosen. In the current study, the smallest (including fewest reactions) reduced mechanism scoring higher than 0.9 (0.7 for the biogenic case, see below) is selected. This reduced mechanism is called A0.90 (A0.70). The entire process takes a few hours on the working desk-top machine used in

\subsection{Cases: Different pollution scenarios}

Mechanisms are generated for the prediction of the target compound sets described below (see Section 2.4 in six cases, previously described by Emmerson and Evans (2009).

The initial conditions for the six cases are derived from an annual simulation of the GEOS-CHEM composition transport model (Bey et al., 2001). The six cases take on values from grid boxes which reach extremes in typical tracer concentration patterns representing six types of environments: Industrial, clean, cold $\&$ dry, hot $\&$ wet, biogenic, and non-biogenic. The initial values of the six cases are tabulated in Table 1. The cases were used to study the six chemistry mechanisms' ability to predict the concentrations of ozone, $\mathrm{NO}_{x}$, nitrate, hydroxyl radical, and PAN for five simulated days (120 hour), starting at midnight local time, in a box model setting. Emmerson and Evans idea is to test the mechanisms in the wide range of condition which are likely to occur in a global 

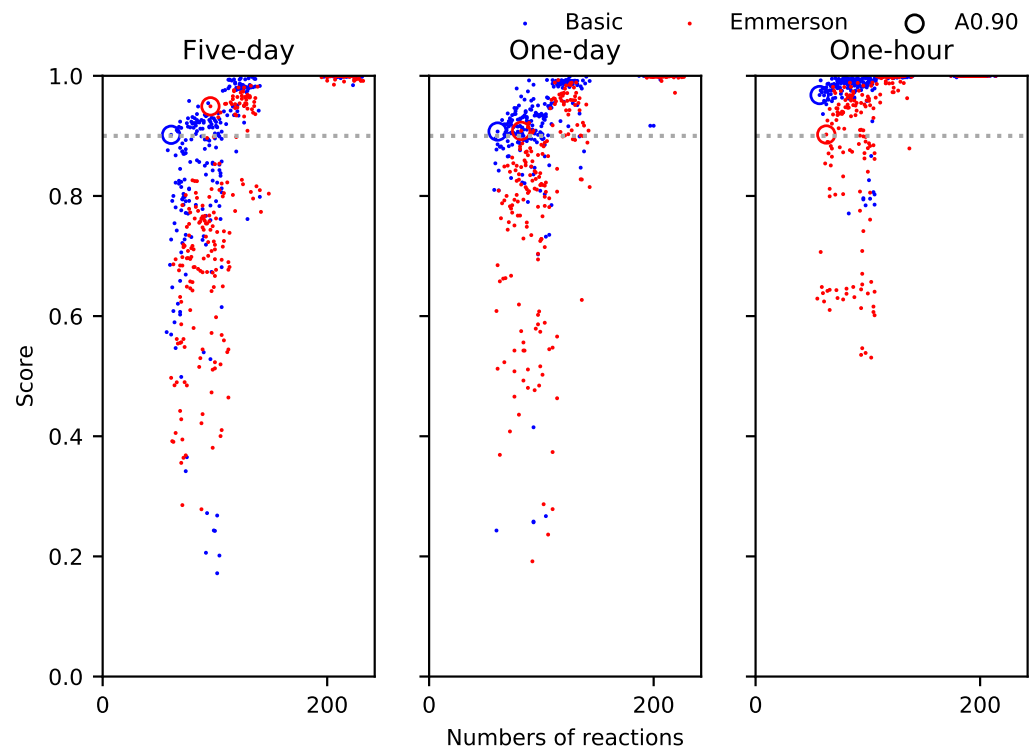

Figure 1: The full selection of accepted mechanisms generated by six entire reduction processes of the hot $\&$ wet case, see Table 1 Mechanisms tuned to the three different time scale are depicted in the three panels (from left to right): Five-day, one-day, and one-hour. Mechanisms tuned to the two target compound sets are depicted with colored dots: Basic (blue) and Emmerson (red). The A0.90 mechanisms are encircled, the grey dotted lines correspond to the cut-off for the score (0.90).

model. In the current study, the idea is to test the method's ability to tailor mechanisms for this wide range of realistic (but simplified) conditions, and to evaluate the inter-variability of the produced mechanisms for the six cases. The five-day time scale and the target compounds are retained in the current study. Emmerson and Evans (2009) use MCM v3.1 as the benchmark. The mean deviation of the target compounds between MCM v3.1 and MCM v3.3.1 formulated as a score with the MCM v3.3.1 used as the base mechanism for all the cases lie between 0.44 and 0.89 , reflecting the development of the MCM mechanism. Direct comparisons between the current simulation results and the benchmark simulation of Emmerson and Evans (2009) are thus not relevant. The mean deviation of the target compounds between MCM v3.1 and MCM v3.3.1 formu- 
lated as a score with the MCM v3.3.1 used as the base mechanism for all the cases are presented in Section S.1 and the time resolved predictions are plotted in Figs. S.1-S.6 in the Supplementary Material.

Two cases include isoprene $\left(\mathrm{C}_{5} \mathrm{H}_{8}\right.$, industrial and biogenic) and four do not. The four non-isoprene cases all share the same initial compound setup, only the initial concentrations of the different compounds are varied. Similarly, the two isoprene cases share the same initial compound setup. The four nonisoprene cases will thus be reduced from (and tested against) one particular subset of the full MCM mechanism (296 reactions, 99 species), and the two isoprene cases will be reduced from another particular subset (2016 reactions, 638 species). The non-isoprene base mechanism corresponds to a MCM subset with methane, ethane, propane, formaldehyde, acetaldehyde, and acetone as parent compounds including inorganic species as can be downloaded from the MCM website (MCM, 2018$)$. All reaction including sulphur are removed. The isoprene base mechanism corresponds to a MCM subset which includes isoprene as well as all the other parent compounds listed above. There is a substantial complexity of the isoprene chemistry (Jenkin et al., 2015, Wennberg et al., 2018); the isoprene chemistry subset covers 1900 reactions, which is about $10 \%$ of the size of the full MCM mechanism. Furthermore, isoprene's two olefinic bonds warrant high reactivity and thus a significant role in ozone chemistry.

The $\mathrm{NO}_{x}$ regime of a system can be indicated by whether the dominant sink of radicals (hydroxyl-, hydroperoxyl-, and organic peroxy radicals) is reactions with $\mathrm{NO}_{x}$ or not (Jacob, 1999). Kleinman et al. (1997) introduces the measure $L_{N} / Q$ as an indicator for the $\mathrm{NO}_{x}$ regime of a system, where $L_{N}$ represents the total rate of all reactions where a radical reacts with either nitric oxide or nitrogen dioxide and $Q$ the total rate of all radical loss reactions. A high $\mathrm{NO}_{x}$ system is defined as a system where $L_{N} / Q>0.5$, a system with $L_{N} / Q<0.5$ is defined as a low $\mathrm{NO}_{x}$ system. Consequently, a system commonly shifts from one regime to another under the course of a day. The average ratios, $\mu\left(L_{N} / Q\right)$, for the cases are tabulated in Table 1. It can be noted that three cases are (on average) in the high $\mathrm{NO}_{x}$ regime: Industrial, cold $\xi$ dry, and non-biogenic and 
three cases are in the low $\mathrm{NO}_{x}$ regime: Clean, hot $\mathcal{E}$ wet, and biogenic. The time resolved $L_{N} / Q$ ratios for the cases are plotted in Figs. S.7-S.13 in the Supplementary Material.

In order to isolate the chemistry's sensitivity of $L_{N} / Q$, mechanisms are reduced for the hot $\&$ wet case with increased levels of nitrogen dioxide, in addition to the cases represented in (Emmerson and Evans, 2009), see the high $\mathrm{NO}_{x}$ rows in Table 1. The initial concentration of $80 \mathrm{ppb}$ nitrogen dioxide is chosen to be comparably high, but not unrealistic. The value is below the official 1-hour health thresholds for nitrogen dioxide, but slightly above the annual mean threshold: The WHO 1-hour average nitrogen dioxide standard is set to $200 \mu \mathrm{gm}^{-3} \approx 100 \mathrm{ppb}$ and the annual nitrogen dioxide standard is set to $40 \mu \mathrm{gm}^{-3} \approx 20 \mathrm{ppb}(\mathrm{WHO}, 2006$ ), the EPA 1-hour average nitrogen dioxide standard is set to $100 \mathrm{ppb}$ and the annual average nitrogen dioxide standard is set to $53 \mathrm{ppb}$ (EPA, 2011).

Finally, one mechanism is generated for the purpose of predicting the target compound concentrations with (on average) high accuracy for all Emmerson and Evans six original cases. This mechanism is named the all-round mechanism.

\subsection{Time scales}

To investigate the methods sensitivity to time scales, mechanisms are tailored to the cases described in Section 2.2 over shorter time scales. The underlying assumption is that shorter time scales offer less time for the chemistry to evolve and therefore the selection of chemical reactions may differ. Furthermore, the exclusion of a period without photolysis (night) is expected to influence the size and characteristics of a reduced mechanism.

Mechanisms are generated for time scales of one day (24 hours) and one hour in addition to the default time scale of five days. One hour corresponds to the time scales of residence time in a confined urban environment that is not efficiently ventilated to the free boundary layer. An hour in the middle of the day is selected. The day time simulations are initialized at 11:30 local time such 
time, as for the simulations with longer time scales. The one-day and five-day simulations will be initialized at midnight.

When considering time scales, also the spin-up time of the model should be taken into account. The spin up allows the concentrations of all uninitialized

\subsection{Reaction categories}

In the analysis of the generated mechanisms seven mutually exclusive categories of reactions are used. There is a hierarchy of the categories, such that 
those reactions that meet the criteria of several categories, fall in the first category for which these criteria is met, as they are listed below:

1. $\mathrm{RO}_{2}+\mathrm{NO}:$ All the reactions in the form $\mathrm{RO}_{2}+\mathrm{NO} \longrightarrow \mathrm{RO}+\mathrm{NO}_{2}$, where an organic peroxy radical reacts with a nitric oxide to produce a nitrogen dioxide.

2. $\mathrm{RH}+\mathrm{OH}$ : All the reactions in the form $\mathrm{RH}+\mathrm{OH} \stackrel{\mathrm{O}_{2}}{\longrightarrow} \mathrm{RO}_{2}+\mathrm{H}_{2} \mathrm{O}$, where an organic compound reacts with a hydroxyl radical to eventually produce an organic peroxy radical.

3. other $N O_{x}$ : Other reactions that have nitric oxide or nitrogen dioxide either as a reactant or a product.

4. other $\mathrm{NO}_{y}$ : Other reactions that have any nitrogen containing compound (predominantly oxidized nitrogen, commonly defined as $\left[\mathrm{NO}_{y}\right] \equiv\left[\mathrm{NO}_{x}\right]$ $+\left[\mathrm{HNO}_{3}\right]+[\mathrm{HONO}]+\left[\mathrm{N}_{2} \mathrm{O}_{5}\right]+\left[\mathrm{ClONO}_{2}\right]+\left[\mathrm{NO}_{3}\right]+\left[\mathrm{HOONO}_{2}\right]+$ $\left.\left[\mathrm{BrONO}_{2}\right]\right)$, either as a reactant or a product. However, all reactions involving nitric oxide or nitrogen dioxide fall into the other $N O_{x}$ category and are not included here. This reaction category is especially associated with night time chemistry.

5. other $H O_{x}$ : Other reactions that have hydroxyl radical or hydroperoxyl radical either as a reactant or a product.

6. other $\mathrm{RO}_{2}$ : Other reactions that have an organic peroxy radical either as a reactant or a product (predominantly peroxy-peroxy reactions).

7. other: All other reaction $\left(\mathrm{O}_{x}\right.$ reactions and unimolecular decomposition of hydrocarbons).

The reaction categories are designed to capture the characteristics of mechanisms beyond size.

\section{Results and discussion}

\subsection{Different pollution scenarios}

The size and the score of all simulations with the A0.90 (A0.70) mechanism of all the cases, as described in Sections 2.1 and 2.2 are tabulated in Table 
2. The extent of reduction in number of reactions and species for the reduced mechanisms, including the all-round mechanism, are presented in Table 3 . All reduced mechanisms are developed for five simulated days using the Emmerson target compound set except where otherwise noted. The threshold for the accuracy based mechanism in the biogenic case is lowered to 0.70 (A0.70), since the method does not return useful mechanisms with accuracy above 0.90 with the current settings. The smallest A0.90 mechanism for the biogenic case generated thus far includes 1734 reactions and 633 species. The partial scores of the A0.90 (A0.70) mechanisms are presented in see Table 4

Since common approaches to chemistry simulations of urban street canyon air quality models are either to use a minimal $\mathrm{O}_{3}-\mathrm{NO}_{x}$-mechanism (Zhong et al. 2016a) or simply regard all compounds as unreactive (no chemistry)

315 (Vardoulakis et al. 2003), the cases are tested with these approaches. Scores obtained by simulations with an $\mathrm{O}_{3}-\mathrm{NO}_{x}$ mechanism, covering only three reactions, and scores calculated by keeping the concentrations constant (no chemistry) are tabulated in Table 2 .

It can be deduced from Tables 24 that the method can successfully generate reduced mechanisms for simple non-isoprene or isoprene lean atmospheric chemistry cases, down to a third or even a tenth the size of a near-explicit chemistry subset without losing more than $10 \%$ accuracy on average of predictions of a set of relevant compounds over at least as long as five days, even if the chemistry is in the $\mathrm{NO}_{x}$-limited regime. Isoprene rich chemistry proved to require larger numbers of reactions to accurately predict the target compound concentrations, especially PAN and hydroxyl radicals (both with partial scores of 0.54 for the A0.70). The all-round mechanisms scored 0.98 or higher for all non-isoprene cases, 0.90 for the industrial case, and 0.56 for the biogenic case.

Generally, the score of the cases with $\mu\left(L_{N} / Q\right)<0.5$ (hot $\mathcal{E}$ wet, clean, and 330 biogenic) are mostly held back by the low accuracy of the PAN prediction, while this is not the case for the cases with higher $\mu\left(L_{N} / Q\right)>0.5$, where the PAN score does not stand out from the other trace gas species prediction scores. 


\subsection{Non-isoprene cases}

\subsubsection{Cases}
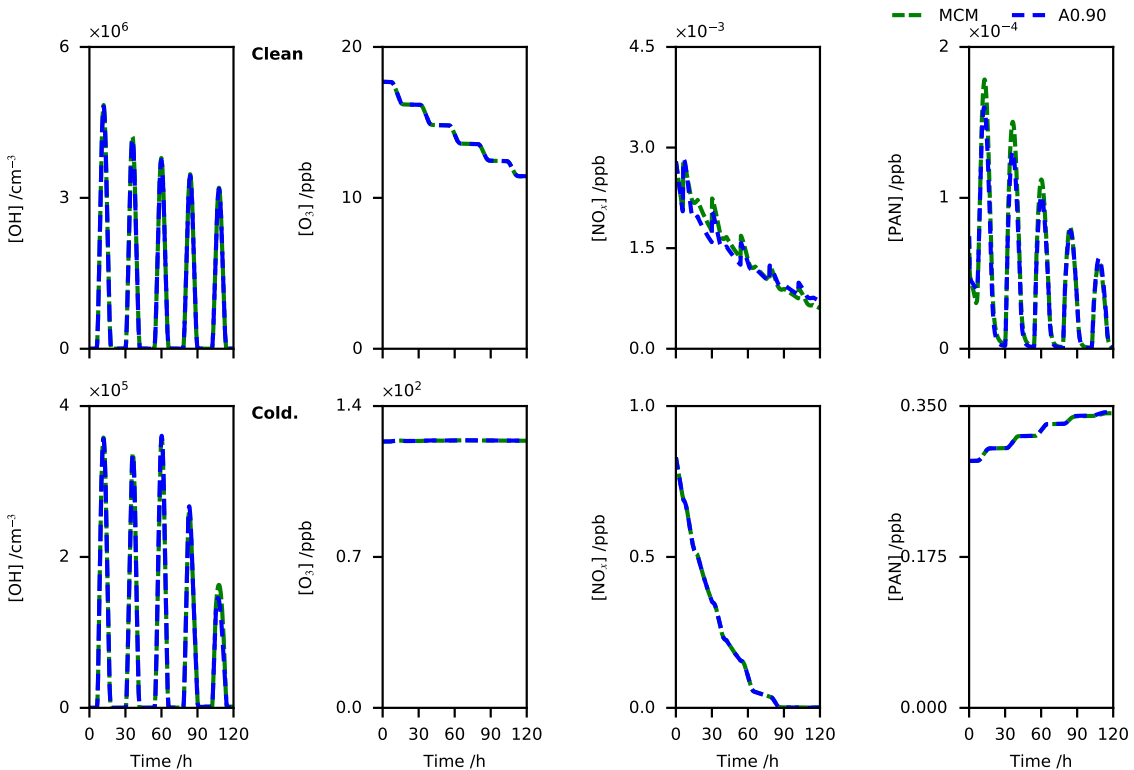

Figure 2: Details of the simulation of the clean (upper panels) and cold $\mathcal{E}$ dry (lower panels) over five days: MCM (green color) and A0.90 mechanisms (blue) broken up compound by compound as (from left) $\mathrm{OH}, \mathrm{O}_{3}, \mathrm{NO}_{x}$, and PAN. All mechanisms are optimized to simulate the Emmerson target compound set. The scoring is described in Eq. (1).

The result of all non-isoprene cases, five-day simulations with the A0.90 mechanism of all the cases are depicted along with the results of the simulation using the non-isoprene MCM subset in Figs. 2 and 3 all developed using the Emmerson target compound set. The result of the high $\mathrm{NO}_{x}$ alteration of the hot $\&$ wet case five-day simulation is depicted in Fig. 4. Additionally, the scores of the prediction of peroxy radical concentrations $\left(\left[\mathrm{HO}_{2}\right]\right.$ and $\left.\left[\mathrm{RO}_{2}\right]\right)$ of the five-day Emmerson non-isoprene mechanism simulations are added to Table 4. The time resolved concentration predictions are plotted in Figs. S.14-S.18 in the Supplementary Material.

Figs. 2 and 3 show very small deviations between the reduced mechanisms and the full MCM predictions. The reactions included in the A0.90-mechanisms, 

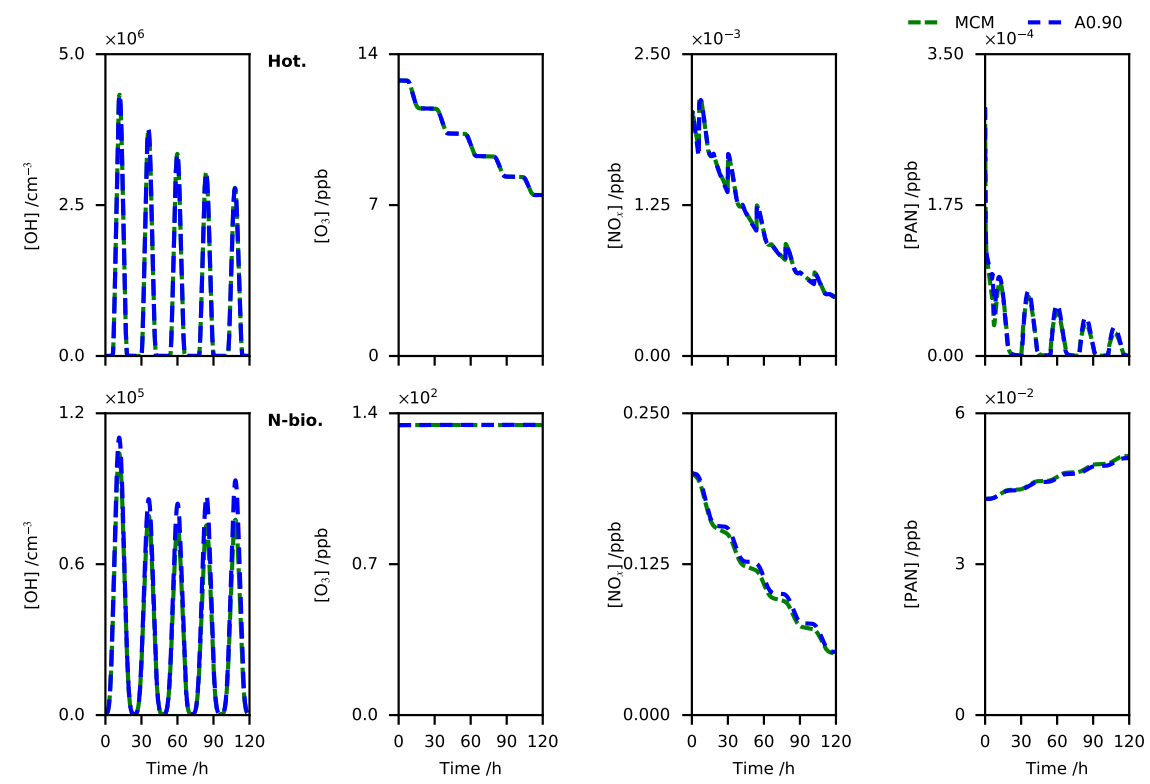

Figure 3: Details of the simulation of the hot $\mathscr{E}$ wet (upper panels) and non-biogenic (lower panels) over five days: MCM (green color) and A0.90 mechanisms (blue) broken up compound by compound as (from left) $\mathrm{OH}, \mathrm{O}_{3}, \mathrm{NO}_{x}$, and PAN. All mechanisms are optimized to simulate the Emmerson target compound set. The scoring is described in Eq. (1).

divided into the reaction categories as defined in Section 2.5 are depicted as bars in Fig. 5, the number of reactions of each category in the MCM subset are depicted as envelope bars. For all the cases the largest absolute reduction is in the other $\mathrm{HO}_{x}$ category (where 73-94 reactions are removed from the MCM subset corresponding to $36 \%-39 \%$ of the total reduction), followed by the other $N O_{x}$ (53-61 reactions corresponding to $23 \%-28 \%$ ), other $\mathrm{RO}_{2}$ (31-40 reactions, corresponding to $15 \%-18 \%), R H+O H$ (19-30 reactions corresponding to $11 \%-12 \%), R O_{2}+N O(10-13$ reactions, corresponding to $4 \%-5 \%)$, other $N O_{y}$ (8-10 reactions, corresponding to about $4 \%$ ), and other (3 reactions, corresponding to $1 \%-2 \%$ ) categories. About a third of the reduction in any of the cases investigated are thus made in the categories concerning hydrocarbons $\left(\mathrm{RO}_{2}+\mathrm{NO}, \mathrm{RH}+\mathrm{OH}\right.$, and other $\left.\mathrm{RO}_{2}\right)$, about a third in the category concerning $\mathrm{HO}_{x}$ reactions without hydrocarbons (other $H O_{x}$ ), and about a third 

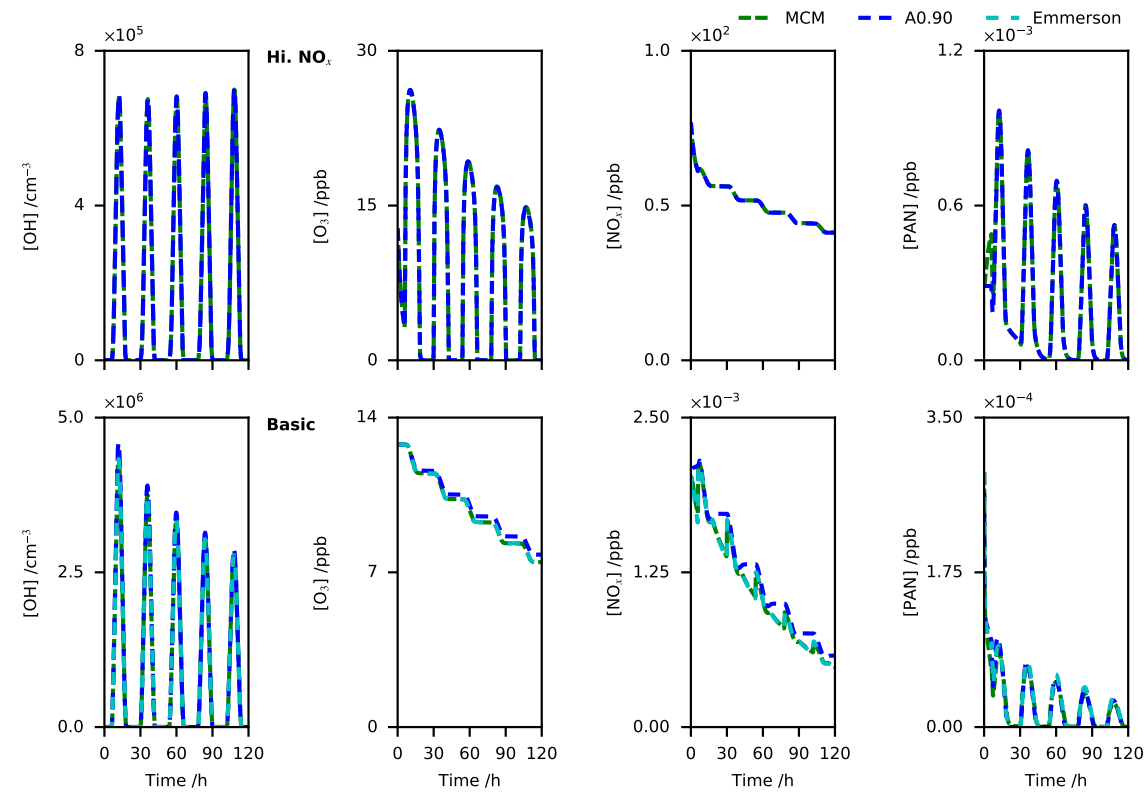

Figure 4: Details of the simulation of the hot $\mathbb{E}$ wet, high $N O_{x}$ (upper panels) and hot $\mathbb{E}$ wet, Basic target set (lower panels) over five days: MCM (green color) and A0.90 mechanisms (blue) broken up compound by compound as (from left) $\mathrm{OH}, \mathrm{O}_{3}, \mathrm{NO}_{x}$, and PAN. In the lower panel the Emmerson target set A0.90 is included for comparison (cyan). The scoring is described in Eq. (1).

in the categories concerning reactions including reactive nitrogen without hydrocarbons (other $N O_{x}$ and other $N O_{y}$ ). Only a small reduction is made in the other category. The absolute reduction scales quite well with the size of the category in the MCM subset: The more reactions that are included in the category, the more reactions are removed by the reduction process. It can be noted, however, that the other $\mathrm{NO}_{y}\left(9 \%-27 \%\right.$ of the reactions are left), other $\mathrm{HO}_{x}$ (11 \%-31\%), and other $\mathrm{RO}_{2}(2 \%-24 \%)$ categories are generally reduced to a higher degree than the $\mathrm{RO}_{2}+\mathrm{NO}(18 \%-37 \%), \mathrm{RH}+\mathrm{OH}(14 \%-45 \%)$, and other $N_{x}(22 \%-32 \%)$ categories for the selected mechanisms. All the A0.90 mechanism have the same set of other reactions, which are the oxygen/ozone regeneration reactions and the decomposition of formaldehyde. The oxygen/ozone regeneration reactions have in the current reduction processes been included in 
the mechanisms automatically and were therefore not explicitly selected by the reduction process. The relatively small size of the non-biogenic mechanism implies that the general level of initial concentrations of the reactants, not only their relative abundance, influence the extent of reduction. This could be the result of smaller variation in reaction channels.

Indication on how the $\mathrm{NO}_{x}$ regime affects the reduction process can be easiest found by comparing the hot $\&$ wet and the hot $\&$ wet, high $N O_{x}$ cases since only the $\mathrm{NO}_{x}$ content differs between the two. The reduction process did render a smaller A0.90 mechanism for the hot $\mathcal{E}$ wet, high $N O_{x}$ than the default hot $\mathscr{E}$ wet case ( 57 reactions, 38 species versus 96 reactions, 57 species). The partial scores (Table 4) give relatively better PAN scores (0.92 for the high $\mathrm{NO}_{x}$ versus 0.80 for the default hot $\&$ wet case). Regarding the composition of reaction categories, Fig. 5 shows that the largest relative difference between hot $\mathscr{E}$ wet and hot $\&$ wet, high $\mathrm{NO}_{x}$ are in the other $\mathrm{RO}_{2}(24 \%$ versus $4 \%), \mathrm{RH}+\mathrm{OH}$ (45\% versus $20 \%$ ), and other $H_{x}$ (31\% versus $11 \%$ ) categories, where the high $\mathrm{NO}_{x}$ case is more reduced. The reduction rate is identical for the $R O_{2}+$ NO (37 \%), other $N O_{x}(29 \%)$, and other $(62 \%)$ categories. The default hot $\&$ wet case is slightly less reduced for the other $N O_{y}$ category (27\% versus $18 \%$ ) than the high $\mathrm{NO}_{x}$ case. $\mathrm{HO}_{x}$ and hydrocarbon chemistry is thus less influential on the chemistry controlling the concentration of the target compounds in the high $\mathrm{NO}_{x}$ regime than in the low $\mathrm{NO}_{x}$ regime, in agreement with established literature (Jacob, 1999).

\subsubsection{Time scales}

To investigate the influence of time scale on the reduction process, two additional reduction processes are run for the Emmerson target compound set, hot \&3 wet case with reduced times scales of one simulated day and one simulated hour, as described in Section 2.3, and the resulting predictions are depicted in Fig. 6. Additionally, the scores of the prediction of peroxy radical concentrations of the one-day and one-hour Emmerson hot 83 wet simulations are added 


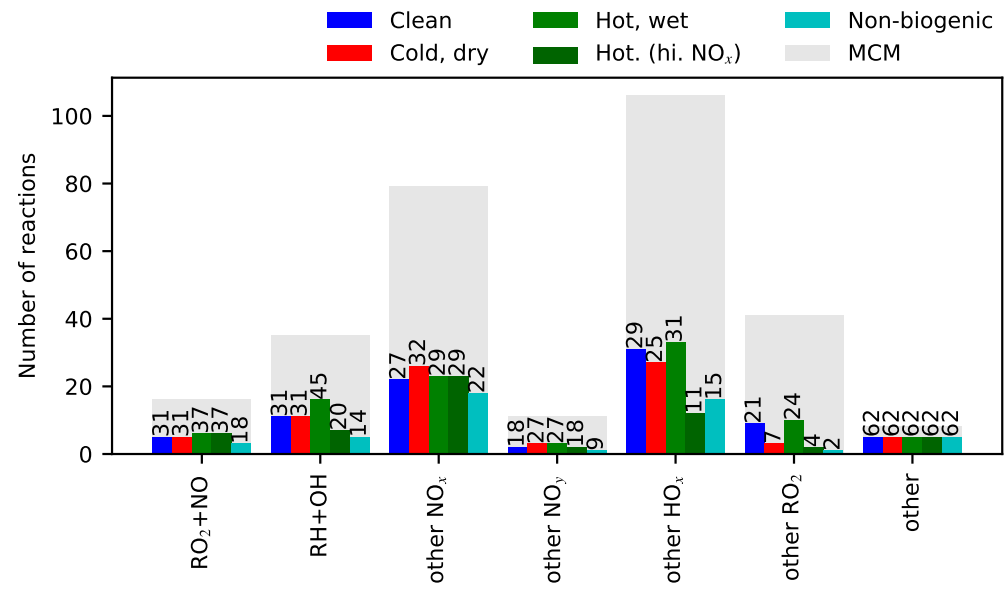

Figure 5: Number of reactions of the A0.90 mechanisms of the non-isoprene cases: Clean (blue color), cold $\&$ dry (red), hot $\&$ wet (light green), and non-biogenic (cyan) including the high $\mathrm{NO}_{x}$ alteration of the hot $\&$ wet case (dark green) five-day simulations generated by ACR for each reactions category with the Emmerson target compound set, the numbers above the bars represent the fraction of the numbers of reactions in the reduced mechanisms to the numbers of reactions in the MCM subset of each category, expressed in percent

and S.20 in the Supplementary Material.

The one-hour A0.90 mechanism is smaller (61 reactions, 36 species) than both the one-day mechanism ( 82 reactions, 49 species) and the five-day mechanism (96 reactions, 57 species). Averaged over all the four non-isoprene cases, generated one-day A0.90 mechanisms are reduced $11 \%$ (three percentage points) more than corresponding generated five-day mechanisms (Emmerson target compound set). Generated one-hour A0.90 mechanisms are reduced 27 \% (seven percentage points) more than the corresponding five-day mechanisms.

The largest difference in partial scores between the one-hour and one-day 410 mechanisms of the target compounds are PAN where the one-day mechanism scores are better than the one-hour ( 0.79 versus 0.64$)$, and the nitric oxide where 

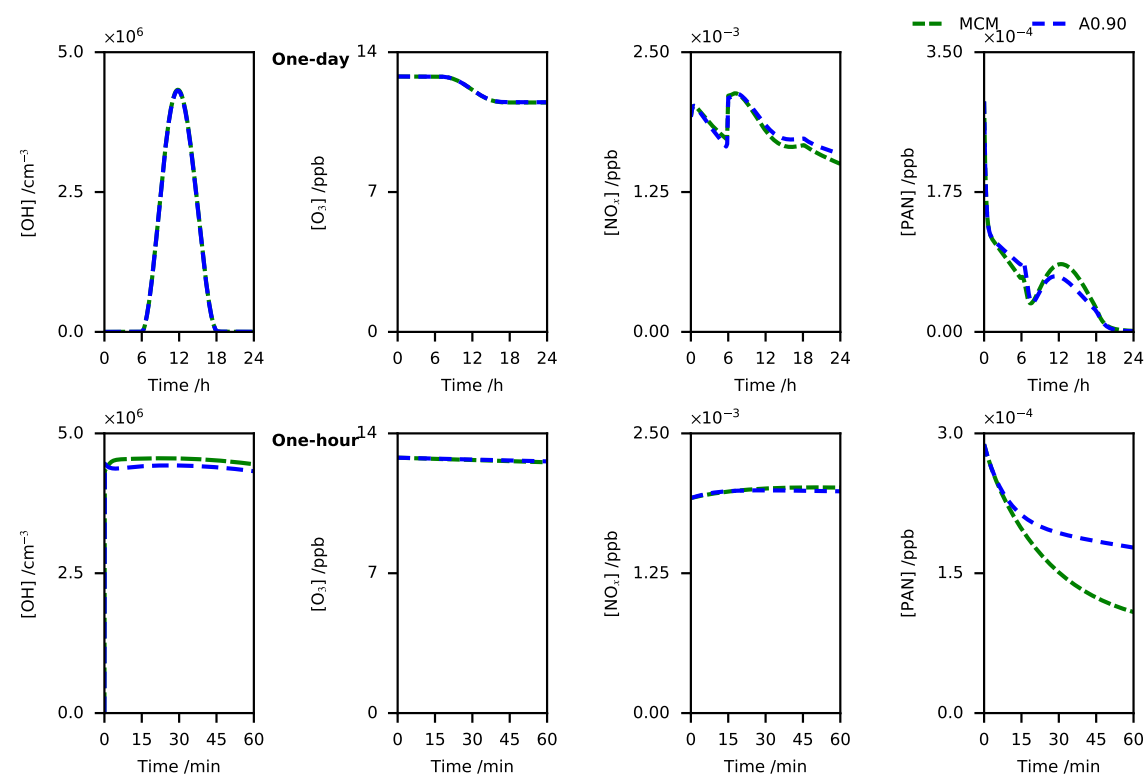

Figure 6: Details of simulations of the hot $\&$ wet case over three different time scales, the lines correspond to the full MCM simulations (green color), the A0.90 mechanisms with the Emmerson target compound set (blue), broken up compound by compound as (from left) $\mathrm{OH}, \mathrm{O}_{3}, \mathrm{NO}_{x}$, and PAN. The scoring is described in Eq. (1).

the one-hour mechanism scores higher than the one-day mechanism (0.96 versus 0.88). Both mechanisms score worse than the five-day mechanism for nitrate (0.85 versus 0.93$)$. It should be noted, however, that nitrate is associated with night time chemistry and is therefore not particularly relevant for the one-hour case. The mechanisms, split up according to the reaction categories as defined in Section 2.5, are depicted as bars in Fig. 7. The one-day mechanism include a larger fraction of other $N O_{x}$ and other $N O_{y}$ reactions than the one-hour mechanism (26\% versus $21 \%$ and $27 \%$ versus $9 \%$ respectively), reflecting the need for a working night time chemistry in the one-day mechanism. Between the five-day mechanisms and the one-day mechanisms, the largest relative difference is in the $\mathrm{RO}_{2}+\mathrm{NO}$ reactions (37\% versus $18 \%$ ). This is presumably due to the twelwe percentage points larger contribution of organic peroxy radicals from the oxidation of the more long lived organic carbons especially with life- 


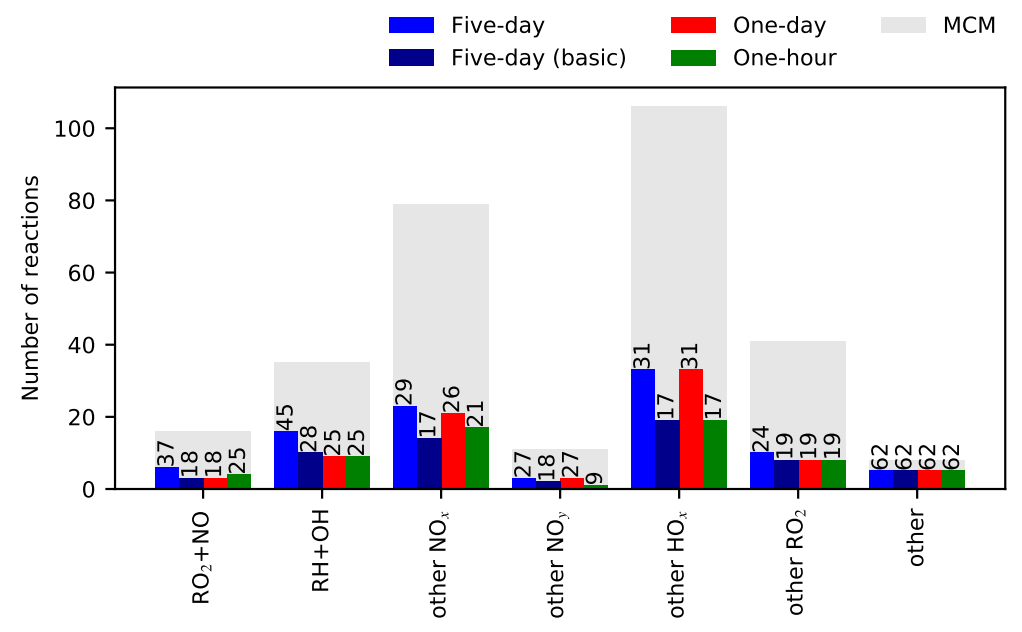

Figure 7: Number of reactions of the A0.90 mechanisms of the hot $\&$ wet case over three different time scales: Five-day (light blue color), one-day (red), one-hour (green) for each reactions category with the Emmerson target compound set along with the five-day Basic target compound set mechanism (dark blue), the numbers above the bars represent the fraction of the numbers of reactions in the reduced mechanisms to the numbers of reactions in the MCM subset of each category, expressed in percent

times on the order of days (mainly methylperoxy radical $\mathrm{CH}_{3} \mathrm{O}_{2}$ reformed from methylhydroperoxid $\mathrm{CH}_{3} \mathrm{OOH}$ ), in the five-day simulations, see Fig. 8 .

\subsubsection{Target compounds}

To test the influence of the choice of target compounds on the reduction process, a reduction was made for the five-day hot $\&$ wet case with the $B a$ sic target compound set in addition to the Emmerson target compound set, as described in Section 2.4, and the resulting predictions depicted in Fig. 4 Additionally, the scores of the prediction of peroxy radical concentrations of the five-day Basic hot 83 wet mechanism simulations are added to Table 4 . The time resolved concentration predictions are plotted in Fig. S.21 in the Supplementary ${ }_{435}$ Material. 


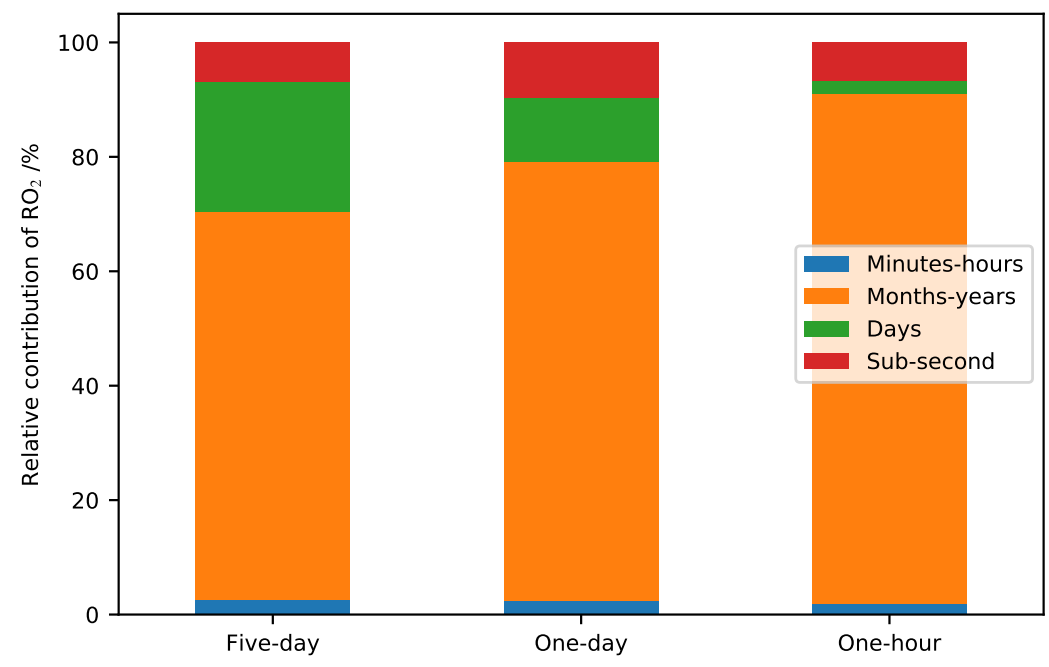

Figure 8: The relative contribution of organic peroxy radical production from reactions with $\mathrm{RO}_{2}$ precursors with lifetimes on the time scale of month to years (orange), days (green), minutes to hours (blue), and under a second (red) for the five-day, one-day, and one-hour base simulations respectively

The Basic A0.90 mechanism is substantially smaller (61 reactions, 36 species) than the corresponding Emmerson mechanism (96 reactions, 57 species). Averaged over all the four non-isoprene cases, generated Basic A0.90 mechanisms are reduced $18 \%$ (five percentage points) more than the corresponding Emmerson mechanisms (five-day).

The largest difference between the two mechanisms of the Emmerson target compounds are nitrate (0.93 verus 0$)$, for which the concentrations collapses in the Basic mechanisms. The hydroxyl radical concentrations are quite well represented in the Basic mechanism (0.89) even if it is not included in the target compound sets. The most visually obvious deviation between the curves in Fig. 4 is arguably the night time behavior of $\mathrm{NO}_{x}$, which is probably connected to the missing nitrate chemistry. It can be noted that the method seems guided by the inclusion of nitrate in the target compound set towards better $\mathrm{NO}_{x}$ 
concentration predictions. The number of reactions in each of the reaction as bars in Fig. 10 along with the all-round mechanism and the hot $\&$ wet mechanism, which represents a non-isoprene mechanism. The largest relative differ- 

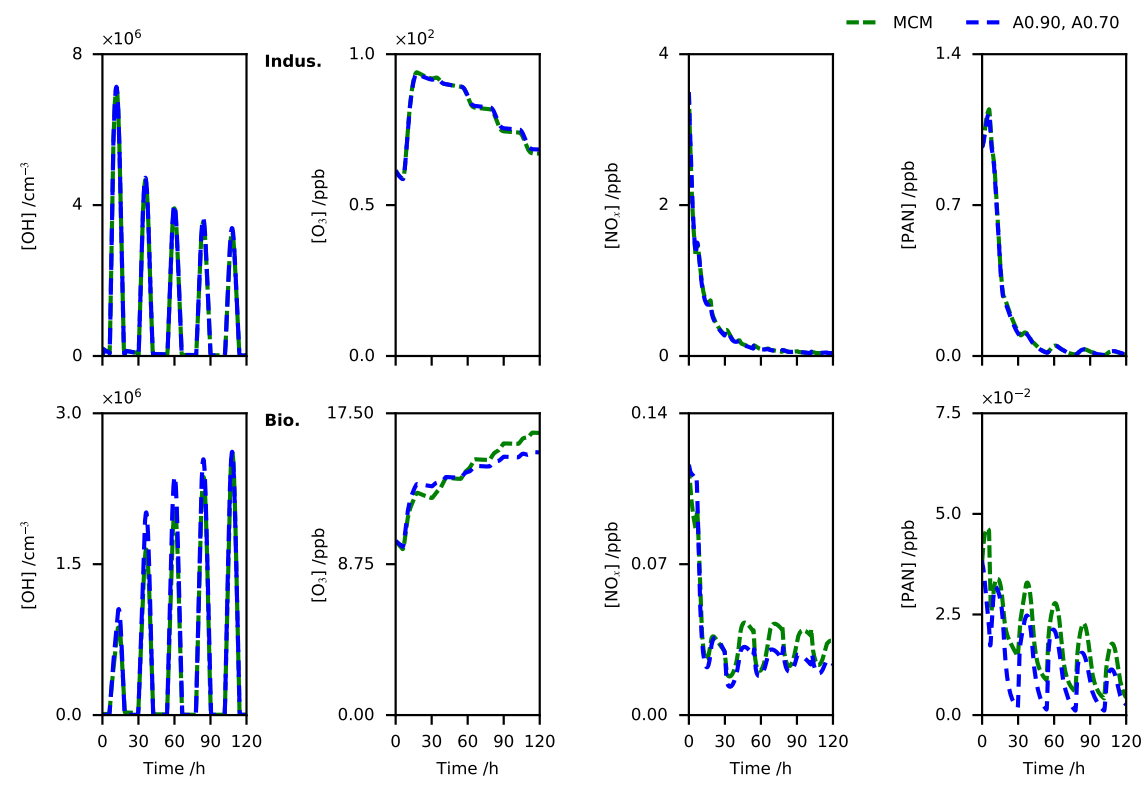

Figure 9: Details of the simulation of the isoprene cases over five days, the full MCM and A0.90 mechanisms (A0.70 for biogenic case) of the case category generated by ACR (blue) broken up compound by compound as (from left) $\mathrm{OH}, \mathrm{O}_{3}, \mathrm{NO}_{x}$, and PAN. All mechanisms are optimized to simulate the Emmerson target compound set. The scoring is described in Eq. (1).

ence between the biogenic case (isoprene rich) and industrial (isoprene lean) is in the $\mathrm{RO}_{2}+\mathrm{NO}$ category where the biogenic case mechanism include $45 \%$ of the $\mathrm{RO}_{2}+\mathrm{NO}$ type reactions, while the industrial case mechanism includes $10 \%$. Even the large all-round mechanism does not include more than $27 \%$. The reason for this is probably the elevated levels of isoprene yielding more organic peroxy radicals. The difference in composition of reaction categories between the industrial case and the hot $\mathscr{E}$ wet case are small (0-10 percentage points). Not only the compositions of reactants, but also their initial concentration will thus influence the reduction. 


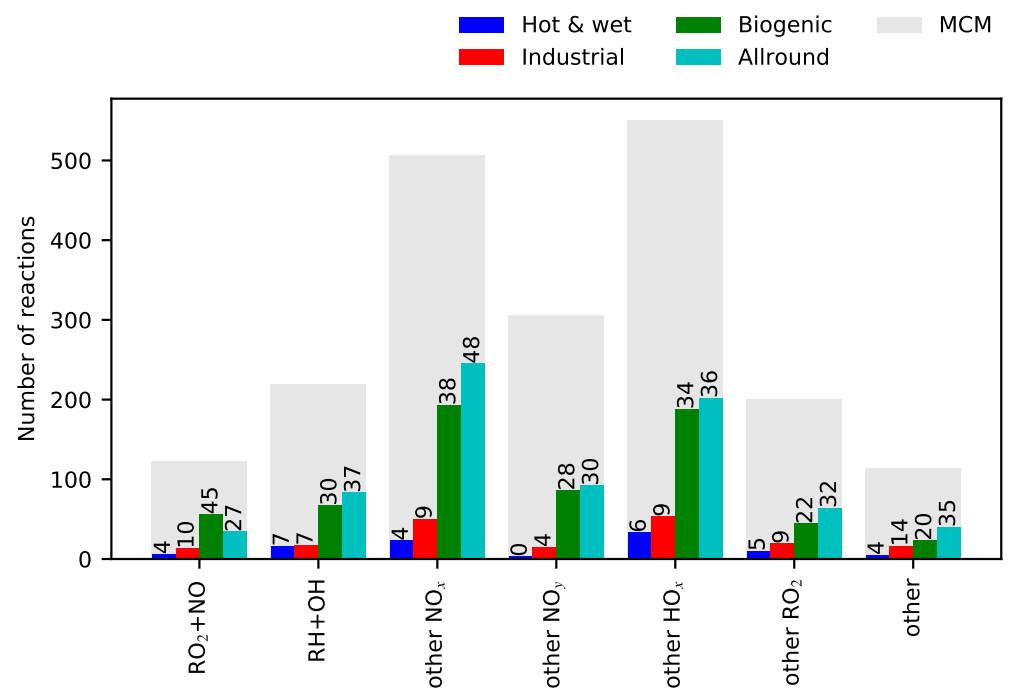

Figure 10: Number of reactions of the A0.90 mechanisms of the five-day simulations of the hot $\&$ wet case (blue color) compared to the two isoprene cases: Industrial (red), biogenic (green), and all-round (cyan) generated by ACR for each reactions category with the Emmerson target compound set, the numbers above the bars represent the fraction of the numbers of reactions in the reduced mechanisms to the numbers of reactions in the MCM subset of each category, expressed in percent. Note that the hot $\&$ wet case here is compared to the MCM subset including isoprene, hence the deviation from the numbers presented in Figs. 5 and 7

\section{Conclusions and Outlook}

Reduced mechanisms generated by the Ant Colony Reduction (ACR) method are here proven able to successfully predict ozone, nitrogen oxides, and other important compounds' concentrations in simulations of several cases up to five simulated days. The mechanisms typically include $10 \%-30 \%$ of all reactions in the relevant subset of the detailed chemical kinetic mechanism (MCM v3.3.1).

The extent of the reduction depends on the time scale, the composition and 495 initial concentration of reactants, $\mathrm{NO}_{x}$ regime, and the compounds of interest. Smallest mechanisms are obtained for cases on shorter time scales with fewer compounds (especially reactive hydrocarbons such as isoprene), lower initial 
concentrations, and fewer compounds of interest. High $\mathrm{NO}_{x}$ cases result in smaller mechanisms compared to low $\mathrm{NO}_{x}$ cases. It is also shown here that these different conditions require different parts of the chemistry; e.g. daytime simulations deselects $\mathrm{NO}_{y}$ reactions to a larger degree than simulations with time scales on the order of days, longer time scales require more $\mathrm{RO}_{2}+\mathrm{NO} \longrightarrow$ $\mathrm{RO}+\mathrm{NO}_{2}$ type reactions, and higher $\mathrm{NO}_{x}$ cases require less hydrocarbon and $\mathrm{HO}_{x}$ chemistry.

Future developments include optimization of reaction rates and emission-, intermediate species-, and reaction lumping. Optimization of reaction rates will compensate loss of reactivity in deselected reactions by turning up the rate of other reactions which have a similar role in the chemistry. Emission lumping will enable reduced mechanisms for large number of hydrocarbons by joining groups of hydrocarbon into surrogate species. Intermediate species lumping will decrease the size of the mechanisms by joining intermediate species into surrogate species and reaction lumping by bypassing fast reaction steps.

The reduction method is very useful for time consuming simulations, e.g. street canyon CFD, where only a limited set of chemical reactions can be included. These environments have a limited complexity and therefore small mechanisms can be tailored without significant loss of accuracy. For climate modeling, where a wide range of species and conditions need to be included, the method extracts larger mechanisms. The use of the method for creating mechanisms for a wide range of conditions will significantly benefit from implementation of further reduction strategies like reaction lumping.

\section{Acknowledgements}

The authors would like to thank Dr. Pontus Roldin for the help with and the permission to use the ADCHAM chemistry module, Dr. Jian Zhong for sharing the box model script used in their work, and Dr. Dennys Angove for sharing measurement data useful in the development of the current method. This work was supported by the Swedish Energy Agency through the project GRECOP 
under the project number 38913-2 and by Crafoordska stiftelsen.

Bey, I., Jacob, D. J., Yantosca, R. M., Logan, J. A., Field, B. D., Fiore, A. M., Li, Q., Liu, H. Y., Mickley, L. J., Schultz, M. G., 2001. Global modeling of tropospheric chemistry with assimilated meteorology: Model description and evaluation. Journal of Geophysical Research: Atmospheres 106 (D19), 23073-23095.

Bright, V. B., 2012. Street canyon atmospheric composition: Coupling dynamics and chemistry. Ph.D. thesis, University of Birmingham.

Bright, V. B., Bloss, W. J., Cai, X., 2013. Urban street canyons: Coupling dynamics, chemistry and within-canyon chemical processing of emissions. Atmospheric Environment 68, 127-142.

Carter, W. P., 2010. Development of the saprc-07 chemical mechanism. Atmospheric Environment 44 (40), 5324-5335.

Carter, W. P., Heo, G., 2013. Development of revised saprc aromatics mechanisms. Atmospheric environment 77, 404-414.

Chen, S., Ren, X., Mao, J., Chen, Z., Brune, W. H., Lefer, B., Rappenglück, B., Flynn, J., Olson, J., Crawford, J. H., 2010. A comparison of chemical mechanisms based on tramp-2006 field data. Atmospheric Environment 44 (33), $4116-4125$.

Damian, V., Sandu, A., Damian, M., Potra, F., Carmichael, G. R., 2002. The kinetic preprocessor KPP-a software environment for solving chemical kinetics. Computers \& Chemical Engineering 26 (11), 1567-1579.

Dorigo, M., Birattari, M., 2011. Ant colony optimization. In: Encyclopedia of 550 machine learning. Springer, pp. 36-39.

Dorigo, M., Maniezzo, V., Colorni, A., 1996. Ant system: optimization by a colony of cooperating agents. IEEE Transactions on Systems, Man, and Cybernetics, Part B (Cybernetics) 26 (1), 29-41. 
Emmerson, K., Carslaw, N., 2009. Night-time radical chemistry during the torch campaign. Atmospheric Environment 43 (20), 3220-3226.

Emmerson, K., Evans, M., 2009. Comparison of tropospheric gas-phase chemistry schemes for use within global models. Atmospheric Chemistry and Physics 9 (5), 1831-1845.

Emmons, L. K., Walters, S., Hess, P. G., Lamarque, J.-F., Pfister, G. G., Fillmore, D., Granier, C., Guenther, A., Kinnison, D., Laepple, T., et al., 2010. Description and evaluation of the model for ozone and related chemical tracers, version 4 (mozart-4).

EPA, 2011. Air quality index for nitrogen dioxide. [ONLINE]. URL https://www3.epa.gov/airnow/no2.pdf

Gery, M. W., Whitten, G. Z., Killus, J. P., Dodge, M. C., 1989. A photochemical kinetics mechanism for urban and regional scale computer modeling. Journal of Geophysical Research: Atmospheres 94 (D10), 12925-12956.

Ginnebaugh, D. L., Liang, J., Jacobson, M. Z., 2010. Examining the temperature dependence of ethanol (E85) versus gasoline emissions on air pollution with a largely-explicit chemical mechanism. Atmospheric Environment 44 (9), 1192-1199.

IPCC, 2013. Summary for Policymakers. Cambridge University Press, Cambridge, United Kingdom and New York, NY, USA, book section SPM, p. 130 . URL Www . climatechange2013.org

Jacob, D., 1999. Introduction to atmospheric chemistry. Princeton University Press.

Jenkin, M., Saunders, S., Wagner, V., Pilling, M., 2003. Protocol for the development of the master chemical mechanism, mcm v3 (part b): tropospheric degradation of aromatic volatile organic compounds. Atmospheric Chemistry and Physics 3 (1), 181-193. 
Jenkin, M., Watson, L., Utembe, S., Shallcross, D., 2008. A Common Representative Intermediates (CRI) mechanism for VOC degradation. Part 1: Gas phase mechanism development. Atmospheric Environment 42 (31), 71857195 .

Jenkin, M., Young, J., Rickard, A., 2015. The MCM v3.3.1 degradation scheme for isoprene. Atmospheric Chemistry \& Physics 15 (20).

Junier, M., Kirchner, F., Clappier, A., van den Bergh, H., 2005. The chemical mechanism generation programme CHEMATA-Part 2: Comparison of four chemical mechanisms for mesoscale calculation of atmospheric pollution. Atmospheric Environment 39 (6), 1161-1171.

Kim, M. J., Park, R. J., Kim, J.-J., 2012. Urban air quality modeling with full $\mathrm{O}_{3}-\mathrm{NO}_{x}-\mathrm{VOC}$ chemistry: Implications for o 3 and pm air quality in a street canyon. Atmospheric Environment 47, 330-340.

Kirchner, F., 2005. The chemical mechanism generation programme CHEMATA-Part 1: The programme and first applications. Atmospheric Environment 39 (6), 1143-1159.

Kleinman, L. I., Daum, P. H., Lee, J. H., Lee, Y.-N., Nunnermacker, L. J., Springston, S. R., Newman, L., Weinstein-Lloyd, J., Sillman, S., 1997. Dependence of ozone production on no and hydrocarbons in the troposphere. Geophysical Research Letters 24 (18), 2299-2302.

Madronich, S., Calvert, G., 1989. The NCAR Master Mechanism of the gas phase chemistry-version 2.0.

MCM, 2018. The Master Chemical Mechanism. [ONLINE].

Monks, P., Granier, C., Fuzzi, S., Stohl, A., Williams, M., Akimoto, H., Amann, M., Baklanov, A., Baltensperger, U., Bey, I., et al., 2009. Atmospheric composition change-global and regional air quality. Atmospheric Environment 43 (33), 5268-5350. 
Naik, V., Voulgarakis, A., Fiore, A. M., Horowitz, L. W., Lamarque, J.-F., Lin, M., Prather, M. J., Young, P., Bergmann, D., Cameron-Smith, P., et al., 2013. Preindustrial to present-day changes in tropospheric hydroxyl radical and methane lifetime from the atmospheric chemistry and climate model intercomparison project (ACCMIP). Atmospheric Chemistry and Physics 13 (10), $5277-5298$.

NCAR, 2018. Atmospheric chemistry observation and modelling. [ONLINE]. URL https://www2.acom.ucar.edu/modeling/ncar-master-mechanism

Pichler, C. S., Nilsson, E. J. K., 2018. Reduced kinetic mechanism for methanol combustion in spark-ignition engines. Energy \& Fuels.

${ }_{620}$ Roldin, P., Eriksson, A., Nordin, E., Hermansson, E., Mogensen, D., Rusanen, A., Boy, M., Swietlicki, E., Svenningsson, B., Zelenyuk, A., et al., 2014. Modelling non-equilibrium secondary organic aerosol formation and evaporation with the aerosol dynamics, gas-and particle-phase chemistry kinetic multilayer model ADCHAM. Atmospheric Chemistry and Physics 14 (15), 7953-7993.

${ }_{625}$ Sanchez, B., Santiago, J.-L., Martilli, A., Palacios, M., Kirchner, F., 2016. CFD modeling of reactive pollutant dispersion in simplified urban configurations with different chemical mechanisms. Atmospheric Chemistry and Physics 16 (18), 12143-12157.

SAPRC, 2013. Atmospheric chemical mechanisms and voc reactivity scales. [ONLINE].

URL https://www.cert.ucr.edu/ carter/SAPRC/

Saunders, S. M., Jenkin, M. E., Derwent, R., Pilling, M., 2003. Protocol for the development of the Master Chemical Mechanism, MCM v3 (Part A): tropospheric degradation of non-aromatic volatile organic compounds. Atmospheric Chemistry and Physics 3 (1), 161-180.

Stockwell, W. R., Kirchner, F., Kuhn, M., Seefeld, S., 1997. A new mecha- 
nism for regional atmospheric chemistry modeling. Journal of Geophysical Research: Atmospheres 102 (D22), 25847-25879.

Vardoulakis, S., Fisher, B. E., Pericleous, K., Gonzalez-Flesca, N., 2003. Modelling air quality in street canyons: a review. Atmospheric Environment 37 (2), $155-182$.

Watson, L., Shallcross, D., Utembe, S., Jenkin, M., 2008. A Common Representative Intermediates (CRI) mechanism for VOC degradation. Part 2: Gas phase mechanism reduction. Atmospheric Environment 42 (31), 7196-7204.

${ }_{645}$ Wennberg, P. O., Bates, K. H., Crounse, J. D., Dodson, L. G., McVay, R. C., Mertens, L. A., Nguyen, T. B., Praske, E., Schwantes, R. H., Smarte, M. D., et al., 2018. Gas-phase reactions of isoprene and its major oxidation products. Chemical reviews 118 (7), 3337-3390.

Whalley, L., Edwards, P., Furneaux, K., Goddard, A., Ingham, T., Evans, M., Stone, D., Hopkins, J., Jones, C. E., Karunaharan, A., et al., 2011. Quantifying the magnitude of a missing hydroxyl radical source in a tropical rainforest. Atmospheric Chemistry and Physics 11 (14), 7223-7233.

WHO, 2006. Air quality guidelines for particulate matter, ozone, nitrogen dioxide and sulfur dioxide-global update 2005-summary of risk assessment, 2006. Geneva: WHO.

Yarwood, G., Jung, J., Whitten, G. Z., Heo, G., Mellberg, J., Estes, M., 2010. Updates to the carbon bond mechanism for version 6 (cb6). In: 2010 CMAS Conference, Chapel Hill, NC. October.( http://www. cmascenter. org/conference/2010/abstracts/emery_updates_carbon_2010. pdf).

Zhong, J., Cai, X.-M., Bloss, W. J., 2016a. Coupling dynamics and chemistry in the air pollution modelling of street canyons: a review. Environmental Pollution 214, 690-704. 
Zhong, J., Cai, X.-M., Bloss, W. J., 2016b. Modelling photochemical pollutants in a deep urban street canyon: Application of a coupled two-box model approximation. Atmospheric Environment 143, 86-107. 
Table 1: Initial values of the test cases as described previously (Emmerson and Evans, 2009), initial concentrations are given in ppb

\begin{tabular}{|c|c|c|c|c|c|c|}
\hline Init. val. & Indus. & Clean & Cold. & Hot. & Bio. & Non-bio. \\
\hline Lon. $/{ }^{\circ} \mathrm{E}$ & 100 & -120 & -5 & -140 & -145 & -160 \\
\hline Lat. $/{ }^{\circ} \mathrm{N}$ & 18 & -30 & -6 & -10 & 26 & -75 \\
\hline Date (mm-dd) & $4-14$ & $2-14$ & $10-11$ & $12-10$ & $7-13$ & $12-31$ \\
\hline Press. / $\mathrm{hPa}$ & 982.6 & 941.6 & $1036.6^{*}$ & 982.6 & 982.6 & $1036.6^{*}$ \\
\hline Temp. /K & 299.7 & 299.4 & 214.4 & 302.7 & 302.5 & 214.3 \\
\hline Rel. hum. $/ \%$ & 46 & 71 & 152 & 71 & 57 & 154 \\
\hline $\mathrm{CH}_{4}$ & 1700.0 & 1700.0 & 1700.0 & 1700.0 & 1700.0 & 1700.0 \\
\hline $\mathrm{CO}$ & 956.5 & 58.4 & 87.6 & 56.9 & 217.7 & 56.1 \\
\hline $\mathrm{NO}_{2}$ & 3.6 & 0.003 & 0.58 & 0.002 & 0.12 & 0.14 \\
\hline$\left(\right.$ high $\left.\mathrm{NO}_{x}\right)$ & & & & 80.0 & & \\
\hline $\mathrm{O}_{3}$ & 63.3 & 19.0 & 86.3 & 13.3 & 10.5 & 93.9 \\
\hline $\mathrm{H}_{2} \mathrm{O}_{2}$ & 11.0 & 1.7 & 0.05 & 1.5 & 8.5 & 0.02 \\
\hline $\mathrm{HNO}_{3}$ & 2.8 & 0.003 & 0.58 & 0.002 & 0.12 & 0.14 \\
\hline $\mathrm{C}_{2} \mathrm{H}_{6}$ & 5.6 & 0.2 & 0.9 & 0.2 & 0.6 & 0.3 \\
\hline $\mathrm{C}_{3} \mathrm{H}_{8}$ & 1.4 & 0.003 & 0.2 & 0.002 & 0.09 & 0.02 \\
\hline $\mathrm{C}_{5} \mathrm{H}_{8}$ & 0.3 & - & - & - & 6.7 & - \\
\hline $\mathrm{HCHO}$ & 6.0 & 0.4 & 0.06 & 0.4 & 4.8 & 0.02 \\
\hline $\mathrm{CH}_{3} \mathrm{CHO}$ & 3.0 & 0.004 & 0.007 & 0.004 & 3.8 & 0.0006 \\
\hline $\mathrm{CH}_{3} \mathrm{COCH}_{3}$ & 17.9 & 1.5 & 2.0 & 1.5 & 15.4 & 0.36 \\
\hline PAN & 1.0 & 0.00008 & 0.2 & 0.0003 & 0.04 & 0.03 \\
\hline$\mu\left(L_{N} / Q\right)$ & 0.52 & 0.34 & 0.66 & 0.34 & 0.40 & 0.55 \\
\hline$\left(\right.$ high $\mathrm{NO}_{x}$ ) & & & & 0.98 & & \\
\hline
\end{tabular}

*The original pressure values are treated as misprint 
Table 2: Size (number of reactions) and score of the A0.90 mechanisms, the $\mathrm{O}_{3}-\mathrm{NO}_{x}$ column reflect the corresponding score obtained with a minimal photostationary state scheme, the No chem. column reflect the corresponding score obtained with constant concentrations. The scoring is described in Eq. (1).

\begin{tabular}{|c|c|c|c|c|}
\hline \multirow[t]{2}{*}{ Case } & \multicolumn{2}{|c|}{ A 0.90} & \multirow{2}{*}{$\mathrm{O}_{3}-\mathrm{NO}_{x}$} & \multirow[t]{2}{*}{ No chem. } \\
\hline & Size & Score & & \\
\hline \multicolumn{5}{|l|}{ Non-isoprene } \\
\hline Clean & 85 & 0.91 & -0.14 & -0.22 \\
\hline Non-biogenic & 49 & 0.93 & 0.06 & 0.15 \\
\hline Cold \& dry & 80 & 0.91 & -0.17 & 0.15 \\
\hline Hot \& wet & 96 & 0.94 & -0.07 & -0.2 \\
\hline high $\mathrm{NO}_{x}$ & 57 & 0.97 & -0.11 & -0.41 \\
\hline basic & 61 & 0.90 & -0.15 & -0.13 \\
\hline one-day & 82 & 0.91 & 0.37 & 0.08 \\
\hline one-hour & 63 & 0.90 & 0.37 & 0.23 \\
\hline \multicolumn{5}{|l|}{ Isoprene } \\
\hline Industrial & 183 & 0.95 & -0.21 & -0.21 \\
\hline Biogenic & $657^{*}$ & $0.74^{*}$ & -0.19 & -0.21 \\
\hline All-round & 760 & 0.90 & -0.12 & -0.09 \\
\hline
\end{tabular}

${ }^{*} \mathrm{~A} 0.70$ 
Table 3: Number of reactions (Reac.) and species (Spec.) of the A0.90 mechanisms and of their corresponding base mechanism (Base mech.), and the fraction $n_{\mathrm{A} 0.90} / n_{\text {base }}$ in $\%$ (Rel. size), where $n$ either is the number of reactions (Reac.) or the number of species (Spec.) for the $\mathrm{A} 0.90$ and the base mechanism respectively.

Case $\quad \begin{array}{cc}\text { A0.90 } & \text { Base mech. } \quad \text { Rel. size /\% }\end{array}$

Reac. Spec. Reac. Spec. Reac. Spec.

\begin{tabular}{|c|c|c|c|c|c|c|}
\hline Non-isoprene & & & & & & \\
\hline Clean & 85 & 46 & 296 & 99 & 28.7 & 46.5 \\
\hline Non-biogenic & 49 & 33 & 296 & 99 & 16.6 & 33.3 \\
\hline Cold \& dry & 80 & 49 & 296 & 99 & 27.0 & 49.5 \\
\hline Hot \& wet & 96 & 57 & 296 & 99 & 32.4 & 57.6 \\
\hline high $\mathrm{NO}_{x}$ & 57 & 38 & 296 & 99 & 19.3 & 38.4 \\
\hline basic & 61 & 36 & 296 & 99 & 20.6 & 36.4 \\
\hline one-day & 82 & 49 & 296 & 99 & 27.7 & 49.5 \\
\hline one-hour & 63 & 38 & 296 & 99 & 21.2 & 38.4 \\
\hline \multicolumn{7}{|l|}{ Isoprene } \\
\hline Industrial & 183 & 111 & 2016 & 638 & 9.1 & 17.4 \\
\hline Biogenic & $657^{*}$ & $398^{*}$ & 2016 & 638 & 32.5 & 62.4 \\
\hline All-round & 760 & 380 & 2016 & 638 & 37.7 & 59.6 \\
\hline
\end{tabular}

*A0.70 
Table 4: Partial and total score of the A0.90 (A0.70) mechanisms for the different cases. The scoring is described in Eq. (1).

\begin{tabular}{|c|c|c|c|c|c|c|c|c|c|}
\hline Case & $\mathrm{O}_{3}$ & $\mathrm{NO}$ & $\mathrm{NO}_{2}$ & $\mathrm{NO}_{3}$ & $\mathrm{OH}$ & $\mathrm{PAN}$ & Tot. & $\mathrm{HO}_{2}$ & $\mathrm{RO}_{2}$ \\
\hline \multicolumn{10}{|l|}{ Non-isoprene } \\
\hline Clean & 1.00 & 0.91 & 0.91 & 0.90 & 0.98 & 0.78 & 0.91 & 0.75 & 0.64 \\
\hline Non-biogenic & 1.00 & 0.96 & 0.96 & 0.80 & 0.89 & 0.99 & 0.93 & 0.94 & -1.0 \\
\hline Cold \& dry & 1.00 & 0.87 & 0.88 & 0.89 & 0.84 & 1.00 & 0.91 & 0.84 & -1.0 \\
\hline Hot \& wet & 1.00 & 0.99 & 0.99 & 0.93 & 0.99 & 0.80 & 0.95 & 0.99 & 0.99 \\
\hline high $\mathrm{NO}_{x}$ & 0.99 & 0.99 & 1.00 & 0.97 & 0.95 & 0.92 & 0.97 & 0.70 & -1.0 \\
\hline basic & 0.97 & 0.87 & 0.86 & 0.00 & 0.89 & 0.40 & $0.67 \dagger$ & 0.32 & -0.42 \\
\hline one-day & 1.00 & 0.88 & 0.96 & 0.85 & 0.97 & 0.79 & 0.91 & 0.63 & 0.69 \\
\hline one-hour & 1.00 & 0.96 & 0.99 & 0.85 & 0.97 & 0.64 & 0.90 & 0.99 & 0.89 \\
\hline \multicolumn{10}{|l|}{ Isoprene } \\
\hline Industrial & 0.99 & 0.97 & 0.97 & 0.94 & 0.91 & 0.96 & 0.96 & 0.85 & 0.67 \\
\hline Biological* & 0.96 & 0.83 & 0.79 & 0.79 & 0.54 & 0.54 & 0.74 & 0.65 & 0.35 \\
\hline All-round & 0.97 & 0.92 & 0.92 & 0.79 & 0.88 & 0.93 & 0.90 & 0.90 & 0.46 \\
\hline
\end{tabular}

$\dagger$ The score is the average of all the partial scores, except $\mathrm{HO}_{2}$ and $\mathrm{RO}_{2}$

*A0.70 